\title{
The work of marriage guidance counsellors
}

\author{
NichOlas TyNDALL \\ B.A. \\ National Marriage Guidance Council, Little Church Street, Rugby
}

\section{Introduction}

The first Marriage Guidance Council was established in the late 1930s. In response to growing concern about the increasing divorce rate, which was then rising to 7000 divorces per annum, a small group of clergy, magistrates, doctors and social workers conceived the notion of establishing an agency which would specifically offer help to people in marital difficulties. Faute de mieux the work was undertaken by volunteers and was carried out with more courage than expertise. The early records show that these pioneers initially saw themselves as primarily a referral service, diagnosing problems under such headings as legal, medical, psychiatric or contraceptive, and guiding clients to the appropriate source of help. The early counsellors were spurred on by what the first Chairman, Dr Herbert Gray, termed a sense of compulsion, not with a clear idea of how they were to achieve their aims, but 'as nobody else was trying, we must needs try' (Holt, 1971).

The post-war years witnessed a rapid expansion in the number of Marriage Guidance Councils, and in 1947 recognition was given by the Denning Committee on Matrimonial Procedures which recommended financial support from public funds. The Home Office accordingly made the first grant-in-aid in 1948 to the National Marriage Guidance Council, the Family Discussion Bureau (now at the Tavistock Institute and renamed the Institute of Marital Studies) and the Catholic Marriage Advisory Council which had by then been established independently by the Catholic Church.

The National Marriage Guidance Council and the Catholic Marriage Advisory Council remain essentially the products of this history. They have preserved their status as voluntary organizations, with the Home Office continuing grant-in-aid, currently providing approximately two-thirds of their income. They also continue to provide a marriage counselling service using voluntary counsellors, now with national coverage. The small number of full-time staff are employed centrally on training, supervision and administrative duties. Counselling itself is still seen as a suitable expression of social concern by appropriate volunteers, though methods of counselling have been developed greatly since the pioneer days, borrowing in particular from psychiatric insights and casework practice. Close links are established between the marriage counselling agencies and the Tavistock, particularly with the Institute of Marital Studies, which contributes substantially to training tutors and supervisors.

Since marital counselling is extremely stressful, great emphasis has been placed from the beginning on careful selection of counsellors to ensure that only people of high potential and integrity are recruited. A rigorous selection procedure is followed by basic training consisting of six residential training sessions; all counsellors are required to attend regular case discussion sessions, and they work under the guidance of a supervisor or tutor. In these days when volunteers are being recruited as social work auxiliaries for work with after-care patients, exprisoners, old people in hospitals and in many other fields, marriage guidance counsellors stand mid-way between the auxiliary and the professional worker. Like the auxiliaries they are part-time voluntary workers, but unlike them they are not carrying a caseload on behalf of a professional worker but are totally autonomous in their counselling. They are indeed volunteers working to a professional standard.

\section{The recruitment of counsellors}

Potential counsellors undergo a two-part selection process. They are first required to be approved by their local Marriage Guidance Council who then sponsor them to attend a day's selection conference centrally. At these conferences three selectors, one of whom until recently has always been a psychiatrist, submit eight candidates to a variety of interviews, personality tests and group exercises, selecting currently about $45 \%$ of them as trainee counsellors (Hooper \& Tyndall, 1972).

In practice, candidates with varying qualifications and experience are selected. The majority are aged 30-50 with a preponderance in their middle and late 30 s. Women outnumber men by nearly 4 to 1 , and practically all candidates are married. Most of the women are housewives seeking to enrich their domestic lives with an occupation in which they can apply their previous training in such varied spheres as social work, teaching, medicine, occupational 
therapy and nursing. This early training, reinforced by their subsequent life experience as wives and mothers, provides a professional basis on which their training for counselling can be built. The men are mainly in full-time employment. They undertake counselling either to complement their professional work as teachers, ministers and personnel officers or to seek the satisfaction in personal service that may be absent in their work in industry, administration or the civil service.

At selection conferences, the selectors are primarily looking for personal qualities rather than academic attainment. Candidates must display the ability to function as counsellors, and this requires some combination of the crucial factors of genuineness, non-possessive warmth and accurate empathy (Truax \& Carkhuff, 1967). Basically conflict-free people are sought who can display 'creative openness' to other people and their problems.

\section{The counselling process}

The counsellor's approach to these problems is fundamentally client-centred. His task is neither to diagnose nor prescribe remedies but rather to share with clients the troubles, doubts and tensions of their marriages. This is essentially a listening process. Husband and wife, together or separately, are given the opportunity to talk about their relationship, the problems that precipitated referral and their feelings of ambivalence, hostility or despair.

Counselling, which always takes place in marriage guidance premises, comprises three elements. Of primary importance is the acceptance of the client by the counsellor. This springs from the counsellor's welcoming and sympathetic attitude and from the conditions in the agency. The counsellor must suspend critical judgment, preserve calm and hear not only what the client is saying but also the music behind the words. Time is of essence here, so it is no mean boast that marriage counselling agencies provide an uninterrupted hour for as many weeks as necessary for clients to talk through their problems.

The response of the counsellor is the second element. It is not enough just to listen. The counsellor is hearing out the client's story, at times asking for clarification, at others guiding him into painful areas, seeking to develop a relationship of trust which can be felt as liberating without being over-threatening. Here the counsellor aims at preserving a delicate balance between over-involvement and detachment. He must be felt by his client to be an ally, yet be sufficiently objective to be a source of help in throwing new light on the marriage.

For those clients who are willing and able to derive benefit from extended counselling the third element in counselling becomes apparent. The relationship between client and counsellor deepens to $\frac{\mathbb{Q}}{\Omega}$ a more personal level, with the possibility of estab- $c .$. lishing a sustaining, growing relationship over weeks $\vec{\Rightarrow}$ or months. In such relationships long-standing $\stackrel{\text { ? }}{+}$ areas of pain in the marriage can be mutually ex-? plored, in the hopes that the understanding and $\overline{-}$. confidence developed in counselling can be carried $\frac{\bar{\sigma}}{\sigma}$ back into the marriage. The client perceives the $\propto$ counsellor no longer merely as an anonymous sounding board or sympathetic shoulder, but as $a-$ person with whom to explore and interact. The client/counsellor interaction may well reflect the $\vec{\omega}$ interaction in the marriage between husband and $\stackrel{S}{\circ}$ wife.

From this description it is apparent that there is no hard line dividing marital counselling, social $\stackrel{\infty}{\circ}$ casework or psychotherapy. All three have a commonic genesis. The differences lie not in the process, but inc the ability and experience of the worker, and in the conditions in the agency. In practice within Marriage $\omega$ Guidance Councils, counsellors work at varying윽 levels of intensity, some at a skilled psychothera- peutic level, others providing the support of a be- $\infty$ friending relationship. They share a common focus, $\frac{\mathbb{}}{\mathbb{D}}$ however, which is the marriage, concentrating on 3 the present situation in the marriage rather than the past individual development of the partners. TRo present marital tensions are what the clients preseat $\vec{\varphi}$ and it is on these that counsellors are trained work.

\section{Training of counsellors}

Such work requires counsellors to possess a high degree of personal insight, to know how to respond $\bar{Q}$ with sensitivity, and to be able to tolerate stress, $\stackrel{2}{\overrightarrow{2}}$ anxiety and inadequacy. Training therefore concen-웅 trates on these areas. By design counsellors are encouraged not to think of themselves as having answers. Their only tool is themselves. The development of counsellors' personal skills takes precedence 3 to acquiring knowledge about psychology, medicine, $;$. the law or other disciplines. Most of the learning is 3 . about inter-personal behaviour, with training arranged in small groups. The six short residential training sessions comprising basic training are spread out over 2 years which is viewed as a time of maturing in counselling (Tyndall, 1971).

Counsellors begin to gain practical experience after the first or second course so that their theoretical $/ \mathrm{N}$ training and practical work complement each other. $N$

In addition to the basic training, all counsellors are expected to attend regular case discussion $\omega$ sessions led by a marriage guidance tutor or external psychiatric or social work consultant. This provides an on-going group support, as well as being the forum where personal competence is exposed to the ${ }_{-}^{-+}$ discussion of colleagues. Individual supervision for $\frac{T}{0}$ 
all counsellors is also provided by tutors as an acknowledgment that in this demanding and somewhat hazardous work counsellors have a continuing need and duty to extend their skill.

\section{Marriage guidance clients}

Being voluntary organizations, marriage guidance agencies attract clients with personal motivation to seek help and no external compulsion. In practice clients vary enormously, with considerable local variations. Nationally, in 1970, 20,000 marriages were counselled by marriage guidance counsellors and 6000 by Catholic marriage counsellors. The clients come from a cross-section of social groupings, though the professional and skilled classes are proportionately more heavily represented than unskilled and semi-skilled classes (Wallis \& Booker, 1958). The latter more readily approach the Probation Service with matrimonial problems, and are more likely to react to marital stress by acting out behaviour rather than finding solace in talk therapy.

Clients present multifarious problems, emotional and practical or both. Early adjustment difficulties are commonly presented, as are problems of longstanding marriages where application to M.G.C. comes at the point at which the marriage is breaking down. Clients come from several sources. Many are referred through other agencies such as Citizens' Advice Bureaux or the social services, some come on the recommendation of doctor, priest or solicitor, and others are self-referred. Particularly since the Divorce Reform Act came into force in 1971, solicitors have become more aware of their duty to refer petitioners who might welcome reconciliation attempts.

Application occurs at all points in marriage, with an even spread ranging from pre-marriage requests to approximately $15 \%$ of clients who have been married more than 20 years. N.M.G.C. statistics for 1970 show 30,000 interviews were conducted with husbands and 51,000 with wives; there were 6000 joint interviews. The number of joint interviews is increasing annually, and one suspects this reflects the growing experience and confidence of counsellors.

Though some councils operate a walk-in service, the bulk of first applications are made by telephone or letter. Nearly $60 \%$ of these first applications are made by wives, about $35 \%$ by husbands, and slightly more than $5 \%$ by both partners together. On average, each marriage receives four to five counselling sessions representing $4 \frac{1}{2}$ hours' counselling. This statistic includes some $25 \%$ of clients who attend once or twice, as well as the $15 \%$ of cases who receive counselling extending over more than six interviews. The differing length of counselling reflects the differing needs of clients. Not all clients require extended counselling. One interview may provide a cathartic experience or possibly may answer some lingering query. For other couples the first interview merely serves to open a door on a whole complex of problems. Clients may respond by accepting the invitation to work at length on these problems or they may be too apprehensive or fearful to return for further counselling. In so far as counselling confronts clients both with present reality and with the challenge of personal change, it is little wonder that clients approach it with mixed feelings.

\section{Discussion}

In this age of rapid expansion in community personal services, the continued existence of voluntary organizations undertaking counselling in such uncharted seas as matrimonial relationships must be questioned. It is not enough to defend their present and future in terms of needs served in the past. No one can be sanguine about the extent to which marriage guidance is providing a sufficient service to counter the unhappiness underlying the current high incidence of marital breakdown.

These organizations have limited aims. They offer people in marital conflict a rational alternative to the dilemma of either ending the partnership by divorce or perpetuating unchanged the marriage with its barriers and tensions. This is a professional task of massive dimensions. It continually provokes a sense of inadequacy in the workers, who so often can do little more than share the stress of the presented marriages. The agency's structure must be organized to help counsellors carry this stress. One means of support is the continuous in-service training programme. The other is the conscious choice of quality rather than quantity, establishing credibility by the standard of work.

The credibility of a voluntary organization such as M.G.C. also relies on preserving a strict code of confidentiality. No information is passed on without the consent of the client, and counsellors make no contacts with third parties, such as spouse, relative, doctor or social worker without the client's full approval. Where referral for additional help is recognized to be necessary, clients are encouraged to make the approach themselves. As far as possible referrals to, for instance, legal advice centres, family planning clinics, doctors or psychiatrists are planned as concurrent to counselling in order to mitigate against feelings in clients of rejection by counsellors.

It is probably true that this purist interpretation of confidentiality is as much to protect the counsellor as the client, but this emphasis also demonstrates the need to preserve, and be seen to preserve, a strict neutrality in matrimonial conflicts. Counsellors are continually under pressure to side with one partner against the other. This is emotional pressure, often at an unconscious level, from clients them- 
selves and often, additionally, more overt forceful pressure from solicitors or other representatives of the spouse. In the face of this pressure the voluntary counsellor needs the security of knowing clearly his own work boundary and that of the agency in which he is counselling. This code of confidentiality is a key factor in delineating this boundary.

Marriage counselling aims to straddle the voluntary field and professionalism. The standard of work is monitored by the professional consultants who lend their services to each council, and who have played a major part in developing the present comprehensive selection and training programme. Though a few counsellors are now paid, marriage counselling remains predominantly a voluntary activity, with M.G.C. tapping the resources of informed concern in the community. Marriage as the most intimate and complex relationship is increasingly recognized to be a partnership in which normal people suffer tensions which can be eased or resolved by sharing them with an empathetic third party. This sharing demands time which can often be the contribution made by the voluntary worker but may be denied the professional under the pressure of his other priorities.

The National Marriage Guidance Council occupies a vital complementary role as a specialist partner of the medical and social work professions. The specific clients of M.G.C. are not in essence different from those seeking professional help elsewhere, but they are individuals or couples who have located the source of their stress in their marital relationship 3 and, however intuitively, recognize their best means $\odot$ of relief lies in working at improving their marriage. $\varsigma$

Yet M.G.C. is more than just an agency in $\overrightarrow{\vec{B}}$ partnership with the professions. It also provides an alternative service for which there is a growing need as social work services become monopolistic. Marriage guidance clients on the whole are those who do not translate their marital tensions into $\triangle$ medical or psychiatric illness nor express their क internal stress in socially deviant behaviour which $\vec{\circ}$ might bring them to the attention of the statutory social services. Our evidence is that there is a mush- $\bar{\omega}$ rooming need for this non-medical non-statutory service, particularly for clients who are bewildered by the rate of social and emotional change in the $\frac{3}{3}$. environment. Marriage guidance is attempting to $\vec{\infty}$ fill this gap in the personal services. Our dilemma is of that we do not possess enough financial or personnel $\omega$ resources to provide this alternative service on a of scale big enough to fill the gap adequately.

\section{References}

Holt, N. (1971) Counselling in Marriage Problems. National Marriage Guidance Council.

HoOPER, D. \& Tyndall, N. (1972) Selecting volunteers. Social Work Today, 2, No. 19, 23.

TruAX, C.B. \& CARKHUfF, R.R. (1967) Towards Effectike Counselling and Psychotherapy. Aldine, Chicago.

TyNDALL, N. (1971) Training of marriage counsellor $\overrightarrow{0}$ Marriage Guidance, 13, No. 5, 711.

WALlis, J.H. \& BOOKER, H.S. (1958) Marriage Counselling Routledge and Kegan Paul, London. 